\title{
El fin del exotismo y sus tramas disciplinarias
}

El fin del exotismo and its Disciplinary Interweavings

\section{Luis Alberto Arrioja Díaz Viruell*}

EL COLEGIO DE MICHOACÁN, larrioja@colmich.edu.mx

Este texto tiene el propósito de invitar al lector a adentrarse en un horizonte de obras que plantean -con gran versatilidad- la crítica disciplinaria y la reconciliación entre la antropología y la historia, ya sea a través de discusiones teóricas, debates interpretativos o planteamientos epistemológicos. Asimismo, es una revisión panorámica de una obra compleja y de mucha vigencia para los estudios antropológicos e históricos de hoy en día.

Palabras Clave: antropología, historia, contexto, tiempo, realidad social.

The objective of this text is to invite readers to explore a horizon of works that posit -with great versatility-a critique of scholarly disciplines accompanied by an initiative to reconcile anthropology and history through theoretical discussions, interpretative debates or epistemological positions. Also, it presents a broad review of a complex corpus of writings that are highly-relevant to anthropological and historical studies today.

KEYworDs: anthropology, history, context, time, social reality.

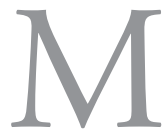

i primer acercamiento con la obra de Alban Bensa ocurrió en el otońo de 2010, cuando Istor. Revista de Historia Internacional publicó atinadamente un artículo -breve y complejo- de su autoría que lleva por título "Antropología e historia”. Debo señalar que este texto fue el preludio para adentrarme en un horizonte de obras que -con gran versatilidad- conducen al lector por el devenir del Pacífico sur, la crítica disciplinaria y, especialmente, la reconciliación entre la antropología y la historia, a la luz

* Este texto es una revisión panorámica de Alban Bensa. El fin del exotismo. Ensayos de antropología critica. Traducción de Daniel Rudy Hiller. Zamora: El Colegio de Michoacán, Secretaría de Cultura, 2016, 271 pp., ISBN 978-607-9470-44-9. 
de enfoques teóricos, argumentos interpretativos, herramientas metodológicas y necesidades epistemológicas.

Conviene advertir que buena parte de la obra de Bensa aparece hoy reunida y traducida al castellano en El fin del exotismo, un libro complejo y sugerente, especialmente para aquellos jóvenes que hoy reciben una formación profesional en el campo de la antropología y la historia; asimismo, para aquellos investigadores que buscan herramientas teóricas y metodológicas para explicar procesos que suelen ser privativos del campo antropológico, histórico y etnohistórico. Cabe decir que El fin del exotismo invita a tener una postura más crítica con las ideas y los enfoques disciplinarios que existen en la antropología y en la historia. En este orden, discute con justa razón los abusos que la antropología social ha cometido al emplear el concepto de "cultura", al plantear estudios sobre sociedades supuestamente primitivas y exóticas, y al limitar sus enfoques analíticos a horizontes sincrónicos. De igual forma, cuestiona aquellos trabajos históricos que demeritan la importancia de los hechos singulares, que desechan -interesada y desinteresadamente- los acontecimientos dentro de la misma historia y que parafrasean las fuentes históricas sin contextualizar sus tiempos e intenciones de creación.

Un rasgo distintivo de esta obra radica en que cuenta con un prólogo de factura excelsa, realizado por Juan Pedro Viqueira, que le permite al lector conocer con lujo de detalle la vastísima trayectoria académica de Alban Bensa; asimismo, lo aproxima a la experiencia profesional del autor, sus compromisos - políticos e intelectualescon el pueblo kanak de Nueva Caledonia, sus quehaceres como antropólogo e historiador, sus críticas hacia el estructuralismo francés y, especialmente, hacia los trabajos antropológicos y etnológicos que omiten por convicción los argumentos de la historia. Así, El fin del exotismo es un libro que invita a la reconciliación disciplinaria; al acercamiento de la antropología y la historia; a la posibilidad de vislumbrar la realidad social como un mundo enteramente histórico donde el tiempo se construye, manipula e interrumpe. Es decir, el tiempo como un elemento consustancial de la realidad social, donde negar su existencia implica privar a la realidad de su característica principal. 
Debe subrayarse que esta obra es una traducción de la versión francesa que apareció en el año 2006 bajo el sello editorial de Anarcharsis Editores y que se distingue de esta edición por tener un mayor número de capítulos, especialmente, orientados a los kanak de Nueva Caledonia. En este sentido, la versión en castellano es un libro estructurado en cuatro partes y diez capítulos, traducido por Daniel Rudy Hiller, y publicado bajo el sello de la Secretaría de Cultura y El Colegio de Michoacán. Una lectura panorámica pone de relieve la existencia de numerosas recomendaciones para vincular la antropología y la historia. Con esta perspectiva, sobresale la reflexión sobre los contextos como horizontes o marcos de los estudios antropológicos e históricos. Así, para Bensa, los contextos deben entenderse como procesos dinámicos, cuyos elementos suelen transformarse a cada momento y vincularse con piezas internas y externas. Dado esto, los contextos son proclives a transformarse, contradecirse o disolverse con el paso del tiempo.

En estrecha relación con los contextos, el autor plantea la necesidad de tomar en cuenta el tiempo histórico, inclusive para instrumentar los análisis más sincrónicos que puedan realizarse, pues, desde la perspectiva de Bensa todo hecho o estructura -social, lingüística, cultural, etcétera- siempre evoca una tensión constante entre las herencias pasadas y las necesidades del presente. Lo anterior se pone en evidencia en el capítulo dedicado a examinar las tensiones que provocan los legados ancestrales y las necesidades del presente entre los canacares de las islas griegas; un estudio que pone al descubierto cómo la tradición, los patrones de filiación, la costumbre marital y las prácticas sociales se modifican, refuncionalizan e incluso desaparecen con el paso del tiempo. No obstante, lo más llamativo del estudio radica en la forma en que Bensa utiliza el tiempo histórico y el trabajo antropológico para construir la explicación sobre un problema reciente en la Grecia contemporánea.

Otro punto sumamente relevante en El fin del exotismo tiene que ver con las escalas de análisis que se formulan en la antropología e historia; escalas que -al no tener una dimensión justa con el objeto de estudio y con los argumentos que se pretenden construir-suelen generar confusiones teóricas, metodologías erradas, anacronismos, 
jerarquías equivocadas, etcétera. Lo anterior puede descubrirse plenamente en aquellos trabajos que superponen al problema de estudio la escala espacial -nación, región, localidad-, sin considerar el influjo que esto puede tener en la investigación y en la comprensión temporal del problema analizado. De ahí la necesidad de ser sumamente críticos con las escalas espaciales, temporales, sociales, etcétera. En este mismo sentido, Bensa dedica algunos capítulos para reflexionar sobre la importancia de los acontecimientos o hechos aparentemente insignificantes en la reflexión antropológica e histórica. Con esta perspectiva, el autor subraya que estos hechos mediáticos guardan mucha importancia e información para comprender a las sociedades, pues, no suelen ocurrir en el vacío; por el contrario, siempre tienen un trasfondo o contexto; asimismo, señala que los acontecimientos no consisten en que ocurra algo, por más importante que el hecho pueda ser, sino en que algo ocurra; es decir, un hecho con devenir, con trasfondo, con problemas que resolver. Sin duda, un acontecimiento no es un simple hecho con una manifestación atractiva. El acontecimiento tiene una raíz profunda en el tiempo histórico y -sobre todo- tiene la capacidad de marcar un antes y un después de su aparición. Suelen ser referencias vitales, inauguran nuevas formas de expresión, nuevos contenidos discursivos, nuevos relatos e interpretaciones, etcétera.

Siguiendo los contenidos de la obra, llama mucho la atención la forma en que el autor formula una crítica constante hacia las ciencias antropológicas y -especialmente- hacia las corrientes analíticas que niegan la existencia de la historia en la antropología. En este orden, el autor plantea que si la antropología es una ciencia social, entonces debe concebirse como una ciencia histórica, sobre todo, rescatando la tradición de Jean Claude Passeron donde todos los hechos en los que interviene el hombre se inscriben en contextos históricos determinados. No obstante, pareciera que el gusto de algunos antropólogos por el estructuralismo y por concebir todas las formas sociales como sistemas simbólicos ha propiciado que la antropología se aleje - poco a poco- de su naturaleza histórica y se plantee como una ciencia que niega el uso de la historia y donde lo prioritario es el estudio del hecho sincrónico, de lo singular en con- 
textos actuales, de manifestaciones simbólicas estáticas y de discursos mediáticos.

Ante esto, Alban Bensa insiste en que todo análisis de un hecho social permite comprender cómo se lleva a cabo una acción en el tiempo y en el espacio, cuáles son sus razones y elementos intrínsecos, dónde se ubican los límites y las conexiones (con el pasado y el presente), y cuáles son los rasgos de su particularidad y generalidad. Bajo esta perspectiva, salta a la vista la reflexión que plantea sobre la etnología y el exotismo cultural. Para ello, utiliza como ejemplo una reflexión sobre el papel que hoy juegan los museos nacionales de etnografía; espacios que - desde la perspectiva gubernamental- sirven para dar materialidad a las culturas originarias; escenarios donde la identidad étnica se adhiere al pasado histórico; recintos donde los objetos son pruebas fehacientes del mundo arcaico y de las culturas exóticas. Con un enfoque crítico, Bensa plantea que dichos museos no son repositorios de información ni mucho menos espacios etnográficos; por el contrario, son receptáculos de obras, espacios de creaciones ficticias y de producciones discursivas oficiales. En este orden, los museos etnográficos son una prueba fehaciente para evidenciar el distanciamiento de la antropología y la historia, y la inclinación de ciertos científicos sociales por fomentar el denominado exotismo cultural.

En términos generales, puede decirse que El fin del exotismo es una obra que nos deja los siguientes apuntes sobre la antropología y la historia. Primero, a la luz del autor, la gran diferencia entre ambas disciplinas radica en las formas en que se interpretan los procesos históricos y los hechos sociales, así como en la importancia que cada una le otorga a la noción de tiempo. En segundo lugar, otra diferencia parece radicar en la manera en que formulan sus explicaciones: los antropólogos, partiendo de casos particulares para enunciar teorías generales; los historiadores, transitando desde lo general hacia lo particular. En este sentido, los historiadores explican los procesos a partir de su causalidad, mientras que los antropólogos tienden a explicarlos desde sus efectos intrínsecos. En tercer lugar, la antropología prioriza el conocimiento de las estructuras y sus componentes, mientras que la historia se inclina por los hechos que se desprenden 
de las estructuras y los contextos que condicionan su naturaleza. En cuarto lugar, salta a la vista que los primeros acercamientos entre ambas disciplinas, con el objeto de formular un conocimiento social más complejo, ocurrió en las décadas de 1960-1969 y 1970-1979 con la antropología funcionalista (G. Balandier y J. Goody) y la antropología estructural-marxista (Evans-Pritchard y M. Sahlins). La historia hizo lo propio en los mismos periodos con la microhistoria (C. Ginzburg y G. Levi) y con la historia comparada (C. Tilly y E. Hobsbawm), ya sea rescatando planteamientos que -desde lo particular- permitían generalizaciones o echando mano de herramientas antropológicas. En sexto lugar, puede decirse que hoy ambas disciplinas tienen una serie de retos comunes. En el caso de la antropología, no perder de vista el peso del tiempo en la formación de procesos, hechos, acontecimientos, espacios, discursos, mitos, etcétera; $y$, sobre todo, el dinamismo que adquieren estos elementos a lo largo de la historia. Sin una perspectiva de esta naturaleza cualquier análisis del tiempo presentará muchas limitaciones. La historia, por su parte, deberá entender que la noción de tiempo es plural, heterogénea y diversa en todo el mundo, especialmente, si se mira más allá de occidente. Tal vez la prueba más fehaciente de este ejercicio pueda encontrarse en la obra de Alban Bensa y en los trabajos de Marshal Sahlins. 